\title{
In vitro antibacterial activity of a silicone-based endodontic sealer and two conventional sealers
}

\section{Marcela WAINSTEIN ${ }^{(a)}$ \\ Renata Dornelles MORGENTAL(a) \\ Silvana Beltrami Gonçalves WALTRICK(a) \\ Sílvia Dias OLIVEIRA ${ }^{(b)}$ \\ Fabiana Vieira VIER-PELISSER(a) \\ José Antonio Poli de FIGUEIREDO(a) \\ Liviu STEIER ${ }^{(c)}$ \\ Cauana Oliva TAVARES(b) \\ Roberta Kochenborger SCARPARO(b)}

(a) Pontifícia Universidade Católica do Rio Grande do Sul - PUCR, School of Dentistry, Department of Clinicals, Porto Alegre, RS, Brazil.

(b) Pontifícia Universidade Católica do Rio Grande do Sul - PUCRS, School of Biosciences, Laboratory of Immunology and Microbiology, Porto Alegre, RS, Brazil.

(c) University of Warwick, Warwick Medical School, Department of Dentistry/ Endodontics, Warwick, United Kingdom.

Declaration of Interests: The authors certify that they have no commercial or associative interest that represents a conflict of interest in connection with the manuscript.

\section{Corresponding Author:}

Renata Dornelles Morgental

E-mail: remorgental@hotmail.com

Doi:10.1590/1807-3107BOR-2016.vol30.0018

Submitted: Jun 30, 2015

Accepted for publication: Sep 02, 2015

Last revision: Sep 30, 2015

\begin{abstract}
The aim of this study was to evaluate whether the modification in the silver component is capable of providing GuttaFlow 2 with antibacterial activity against Enterococcus faecalis compared with epoxy resin-based (AH Plus) and zinc oxide and eugenol-based (Endofill) sealers. The antibacterial activity was evaluated using a reference strain of E. faecalis (ATCC 29212). Freshly mixed sealers were subjected to the agar diffusion test (ADT), while the direct contact test (DCT) was performed after materials setting. ADT results were obtained through measurements, in millimeters, of the inhibition zones promoted by the materials, using a digital caliper. In DCT, values of CFU/mL promoted by the three sealers were compared in three experimental periods ( $1 \mathrm{~min}, 1 \mathrm{~h}$, and $24 \mathrm{~h}$ ). The data were analyzed using Kruskal-Wallis and Dunn post-hoc tests ( $\mathrm{p}$ 0.05). In both ADT and DCT, GuttaFlow 2 presented no effect against E. faecalis, while Endofill and AH Plus showed similar inhibition zones. Endofill was the only material capable of reducing bacterial growth in DCT. In conclusion, modifications in the silver particle of GuttaFlow 2 did not result in a sealer with antibacterial effect against $E$. faecalis.
\end{abstract}

Keywords: Root Canal Filling Materials; Root Canal Obturation; Enterococcus faecalis.

\section{Introduction}

Endodontic treatment aims to promote root canal disinfection, preventing microorganisms from impairing periapical healing or even contributing to the development of apical lesions. ${ }^{1}$ In this regard, Enterococcus faecalis is frequently found in treatment-resistant cases. This Gram-positive coccus presents the ability to invade dentinal tubules and withstand prolonged nutritional deprivation. ${ }^{2}$ In this context, root canal fillings are intended to ensure three-dimensional sealing and, thus, prevent the survival of microorganisms that may be left after instrumentation. ${ }^{1,3}$ Moreover, endodontic sealers presenting antibacterial activity are desirable for suppressing bacterial growth and preventing biofilm development. ${ }^{4}$

GuttaFlow $^{\circledR}$ is a self-curing filling system for root canals comprised of gutta-percha powder (particle size of less than $30 \mu \mathrm{m}$ ), polydimethylsiloxane, silicon oil, paraffin oil, platinum catalyst, zirconium dioxide, silver nanoparticles, and staining. It presents adequate chemical and physical properties $^{5}$ that allow sealing quality and biocompatibility. ${ }^{6,7}$ The 
reported characteristics of GuttaFlow include higher homogeneity and adhesion to the canal walls, as well as appropriate film thickness and flow. Additionally, a slight expansion of this material was observed during setting, helping prevent microleakage. ${ }^{8}$ Regarding antimicrobial activity, the first composition of GuttaFlow showed no effect against Candida albicans, ${ }^{9}$ E. faecalis, and Proteus vulgaris. ${ }^{10}$ On the other hand, the incorporation of low concentrations of insoluble antibacterial nanoparticles in the GuttaFlow original formulation exhibited significant and stable antimicrobial properties. ${ }^{11}$

More recently, another version of the material - GuttaFlow 2 - was produced, containing similar components of the original GuttaFlow, differing basically in the form of silver particle used. ${ }^{12}$ According to the manufacturer, the micro-silver of GuttaFlow 2 provides protection against root canal reinfection. ${ }^{13}$ The effects of this material on microorganisms involved in resistant root canal infections are yet to be elucidated.

Accordingly, the aim of this study was to evaluate whether the modification in the silver antibacterial component is capable of providing GuttaFlow 2 with antimicrobial activity against E. faecalis. Preexisting, commonly used sealers, such as epoxy resin-based (AH Plus) and zinc oxide, and eugenol-based (Endofill) materials were used for comparison of antibacterial activity.

\section{Methodology}

The microbiological assays were carried out under aseptic conditions in a laminar flow chamber (Quimis, Diadema, Brazil). To compare the antibacterial effect of GuttaFlow 2 (Coltène/Whaledent, Langenau, Germany), AH Plus (Dentsply De-Trey, Konstans, Germany), and Endofill (Dentsply, Petrópolis, Brazil), these sealers were mixed in accordance with the manufacturers' instructions. Freshly mixed sealers were subjected to the agar diffusion test (ADT), while the direct contact test (DCT) was applied $13 \mathrm{~h}$ after mixing materials, considering the period needed for the setting of all materials. ${ }^{14}$

The antibacterial activity was evaluated using a reference strain of E. faecalis (ATCC 29212). The microorganisms were grown in brain heart infusion - BHI - broth (Merck, Darmstadt, Germany) at $37^{\circ} \mathrm{C}$ for 18 hour. Then, a bacterial suspension was prepared with $0.85 \%$ saline solution to match the turbidity equivalent to a $0.5 \mathrm{McF}$ arland standard, corresponding to $3 \times 10^{8}$ colony-forming units $(\mathrm{CFU}) / \mathrm{mL}$.

\section{Agar diffusion test (ADT)}

Ten replica plates containing BHI agar were spread with $0.1 \mathrm{~mL}$ of $E$. faecalis adjusted suspension using a Drigalski loop. Then, three wells measuring $6 \mathrm{~mm}$ in diameter and $4 \mathrm{~mm}$ in depth were made with a punch by removing the agar at equidistant points. The wells were immediately filled with one of the three tested materials. Other two plates with three wells, without bacterial suspension, were prepared as controls: one of them received the sealers and aimed to control their contamination, while the other one did not receive the sealers and aimed to control the sterilization of the culture medium. All plates were maintained at room temperature for $2 \mathrm{~h}$ for pre-diffusion of the materials and then incubated at $37^{\circ} \mathrm{C}$ for $48 \mathrm{~h}$ under aerobic conditions. The inhibition zone around each well was measured in millimeters with a digital caliper (Digimess, São Paulo, Brazil).

\section{Direct contact test (DCT)}

The methodology used herein was adapted from Heyder et al. ${ }^{15}$ The experiment was performed in triplicate. The endodontic sealers were applied in 24 -well cell culture plates. About $18 \mathrm{mg}$ of sealer was weighed and placed on the bottom of each well. The plates were incubated at $37^{\circ} \mathrm{C}$ simulating clinical conditions of temperature and humidity for setting.

The sealers were then covered with $400 \mu \mathrm{L}$ of $\mathrm{BHI}$ broth, and $100 \mu \mathrm{L}$ of bacterial adjusted suspension was added per well. The same amount of culture medium with sealer and $100 \mu \mathrm{L}$ of saline solution (without bacterial suspension) was used as negative control, whereas $100 \mu \mathrm{L}$ of bacterial suspension with baseline cell concentration, mixed with $400 \mu \mathrm{L}$ BHI broth without the sealer, was used as positive control.

After $1 \mathrm{~min}, 1 \mathrm{~h}$, and $24 \mathrm{~h}$, the survival of bacteria in each well was evaluated by 10 -fold serial dilutions up to $10^{-7}$, and three aliquots of $20 \mu \mathrm{L}$ from each dilution were cultured on $\mathrm{BHI}$ agar plates. The plates were then incubated at $37^{\circ} \mathrm{C}$ for $24 \mathrm{~h}$, and the $\mathrm{CFU} / \mathrm{mL}$ were counted. 


\section{Statistical analysis}

Inhibition zones obtained in ADT were compared using Kruskal-Wallis and Dunn post-hoc tests. In $\mathrm{DCT}, \mathrm{CFU} / \mathrm{mL}$ values for the three sealers were submitted to log transformation and then compared using Kruskal-Wallis and Dun post-hoc tests in each experimental period. The Friedman test was applied for comparisons between experimental periods for each sealer. The significance level was set at $5 \%$.

\section{Results}

\section{Agar diffusion test (ADT)}

ADT showed that GuttaFlow 2 presented no effect against E. faecalis. GuttaFlow 2 presented inferior antibacterial performance compared with the other two materials $(\mathrm{p}<0.05)$, while AH Plus did not differ from Endofill. The measurements of inhibition zones can be observed in Table.

\section{Direct contact test (DCT)}

Bacterial count showed that Endofill presented superior capacity of inhibiting bacterial growth $(p<0.05)$ only after 24 hour. In the other experimental periods, all sealers were similar to the positive control. By comparing antibacterial activity in the three experimental periods, both AH Plus and GuttaFlow 2 showed a bacterial count similar to that of the control group (no sealer). Only Endofill showed similar numbers of $\mathrm{CFU} / \mathrm{mL}$, comparing 1 and $24 \mathrm{~h}$ (Figure).

\section{Discussion}

The present study revealed that, although GuttaFlow 2 altered its formulation to improve antimicrobial activity, the addition of silver microparticles did not exert an effect against $E$. faecalis. Previous investigations pointed out that the original formulation of GuttaFlow does not present antimicrobial activity, ${ }^{9,10}$ and thus

Table. Mean inhibition zones and standard deviation observed in the agar diffusion test (ADT) for tested sealers.

\begin{tabular}{cccc}
\hline & AH Plus & EndoFill & GuttaFlow 2 \\
\hline Inhibition zones $(\mathrm{mm})$ & $9.47(0.42)^{\mathrm{A}}$ & $8.46(0.28)^{\mathrm{A}}$ & $0.00(0.00)^{\mathrm{B}}$ \\
\hline
\end{tabular}

Distinct letters indicate statistically significant difference between sealers $(p<0.05)$. the silver nanoparticles were solely responsible for promoting a preservative effect. ${ }^{16}$

Silver particles present antimicrobial potential, which is manifested by anchorage to or penetration into the bacterial cell wall, and modulation of cellular signaling by dephosphorylating putative key peptide substrates on tyrosine residues. ${ }^{17}$ Moreover, growth inhibition promoted by silver particles has been associated with the uptake of free silver ions followed by disruption of ATP production and DNA replication and with the generation of silver ions of reaction oxygen species (ROS). ${ }^{18}$

In a recent study, these particles have demonstrated antibacterial activity against $E$. faecalis biofilm when used as an intracanal dressing. On the other hand, when applied as an irrigant solution, silver particles did not affect the biofilm, which was related to their concentration and to the short period of contact with microorganisms. ${ }^{19}$

Moreover, it is clearly established that these particles present a dose-dependent effect, ${ }^{17}$ which could be related to the present results. Although the manufacturer does not reveal the dose of silver microparticles in GuttaFlow 2, it is possible that the minimum inhibitory concentration was not reached in the sealer formulation. This is even more important if one considers that E. faecalis was the microorganism used in the present

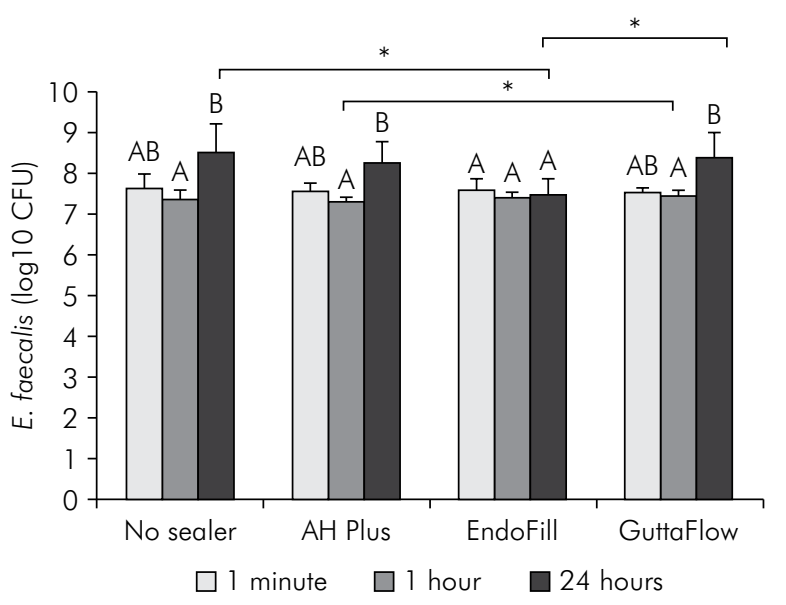

Figure. Enterococcus faecalis survival after incubation with sealers in different experimental periods in the direct contact test (DCT). Distinct letters indicate statistically significant difference between periods for each sealer. Horizontal bars indicate statistically significant difference between sealers in each period $\left({ }^{*} p<0.05\right)$. 
experiment, since it was demonstrated that the effects of silver particles are more pronounced against Gram-negative microorganisms. ${ }^{17}$

In this regard, E. faecalis was selected to evaluate the capacity of sealers to inhibit species related to endodontic failure. E. faecalis is commonly detected in asymptomatic persistent endodontic infections and its prevalence ranges from 24 to $77 \%{ }^{2}$ The high prevalence of this bacterium is related to its capacity of competing with other microorganisms and adapting to adverse conditions. ${ }^{20}$ Moreover, E. faecalis is resistant to several irrigants and intracanal medications used in endodontics. ${ }^{21}$

Given that the persistence of this microorganism in root canals and dentinal tubules is one of the factors affecting endodontic success, ${ }^{2,20}$ the capacity of endodontic filling materials to act against $E$. faecalis can be considered an important advantage. In this regard, the present results showed that in ADT - which evaluated freshly mixed sealers - GuttaFlow 2 presented inferior antibacterial performance compared with AH Plus and Endofill, while, in DCT - after setting of the sealers - only Endofill inhibited bacterial growth over time.

In $\mathrm{ADT}$, the antibacterial activity of a sealer is influenced by the solubility and diffusivity of the material in the medium. ${ }^{16}$ Thus, GuttaFlow 2 is likely to present a lower diffusive ability compared with Endofill and AH Plus sealers, which has contributed to the absence of inhibition zones. Nevertheless, this test cannot distinguish between the microbiostatic and microbiocidal properties of the material. ${ }^{22} \mathrm{In}$ this regard, DCT was employed to measure the effect of direct and close contact between sealers and bacteria. For this test, a period of $13 \mathrm{~h}$ after the sealers were mixed was considered, allowing for the complete setting of all materials ${ }^{14}$. Thereafter, periods of $1 \mathrm{~min}, 1 \mathrm{~h}$, and $24 \mathrm{~h}$ were established for evaluating bacterial growth over time. The current results evidenced that Endofill inhibited bacterial growth after $24 \mathrm{~h}$, corroborating the outcomes of previous studies with ZOE cements. ${ }^{23}$ As a matter of fact, eugenol in the sealer formulation has been described as a potent antimicrobial agent. ${ }^{24}$

As demonstrated, AH Plus was effective against E. faecalis in ADT and in short-term DCT. Kayaoglu et al. ${ }^{25}$ stated that AH Plus antimicrobial activity can be observed in short-term periods, which could be related to the toxicity of some unpolymerized components, such as unset epoxy resin and amines, as shown by other authors. On the other hand, changes in the size of silver particles of GuttaFlow 2 probably contributed to the poor effect of this sealer against E. faecalis. As a matter of fact, it was found that silver microparticles present a smaller number of atoms on their surface compared with silver nanoparticles, ${ }^{26}$ which may result in reduced antimicrobial activity.

Therefore, further modifications should be made in order to improve the antimicrobial activity of GuttaFlow 2. One of the possibilities is to test modifications on the surface of silver particles. In this regard, the addition of surfactant/polymers was tested by Kvitek et al., ${ }^{27}$ which enhanced the antibacterial effects of silver particles. Moreover, it seems that the concentration of these particles should be adjusted to promote an effective antimicrobial activity. ${ }^{17}$

\section{Conclusion}

Modifications in silver particle size of GuttaFlow 2 did not result in a sealer with antibacterial effect against $E$. faecalis.

\section{Acknowledgments}

This study was supported by grants from Fundação de Amparo à Pesquisa do Estado do Rio Grande do Sul - FAPERGS, a Brazilian Governmental Institution (protocol\#1367 12-0). 


\section{References}

1. Nair PN. On the causes of persistent apical periodontitis: a review. Int Endod J. 2006;39(4):249-81. doi:10.1111/j.1365-2591.2006.01099.x

2. Stuart CH, Schwartz SA, Beeson TJ, Owatz CB. Enterococcus faecalis: its role in root canal treatment failure and current concepts in retreatment. J Endod. 2006;32(2):93-8. doi:10.1016/j.joen.2005.10.049

3. Bystrom A, Sundqvist G. Bacteriologic evaluation of the efficacy of mechanical root canal instrumentation in endodontic therapy. Scand J Dent Res. 1981;89(4):321-8.

4. Faria-Junior NB, Tanomaru-Filho M, Berbert FL, Guerreiro-Tanomaru JM. Antibiofilm activity, $\mathrm{pH}$ and solubility of endodontic sealers. Int Endod J. 2013;46(8):755-62. doi:10.1111/iej.12055

5. Zhou HM, Shen Y, Zheng W, Li L, Zheng YF, Haapasalo M. Physical properties of 5 root canal sealers. J Endod. 2013;39(10):1281-6. doi:10.1016/j.joen.2013.06.012.

6. Ozcan E, Eldeniz AU, Aydinbelge HA. Assessment of the sealing abilities of several root canal sealers and filling methods. Acta Odontol Scand. 2013;71(6):1362-9. doi:10.3109/00016357.2012.762990

7. Accardo C, Himel VT, Lallier TE. A novel GuttaFlow sealer supports cell survival and attachment. J Endod. 2014;40(2):231-4. doi:10.1016/j.joen.2013.08.029

8. Kangarlou A, Dianat O, Esfahrood ZR, Asharaf H, Zandi B, Eslami G. Bacterial leakage of GuttaFlow-filled root canals compared with Resilon/Epiphany and Gutta-percha/AH26-filled root canals. Aust Endod J. 2012;38(1):10-3. doi:10.1111/j.1747-4477.2010.00267.x

9. Ozcan E, Yula E, Arslanoglu Z, Inci M. Antifungal activity of several root canal sealers against Candida albicans. Acta Odontol Scand. 2013;71(6):1481-5. doi:10.3109/00016357.2013.771405

10. Farmakis ET, Kontakiotis EG, Tseleni-Kotsovili A, Tsatsas VG. Comparative in vitro antibacterial activity of six root canal sealers against Enterococcus faecalis and Proteus vulgaris. J Investig Clin Dent. 2012;3(4):271-5. doi:10.1111/j.2041-1626.2012.00159.x

11. Kesler Shvero D, Abramovitz I, Zaltsman N, Perez Davidi M, Weiss EI, Beyth N. Towards antibacterial endodontic sealers using quaternary ammonium nanoparticles. Int Endod J. 2013;46(8):747-54. doi:10.1111/iej.12054

12. Mandal P, Zhao J, Sah SK, Huang Y, Liu J. In vitro cytotoxicity of guttaflow 2 on human gingival fibroblasts. J Endod. 2014;40(8):1156-9. doi:10.1016/j.joen.2014.01.025. Epub 2014 Mar 20.

13. Coltène [internet]. City: Coltène; c2015 [cited 2014 Sep 23]. Available from: http://www.coltene.com/download.php?\%20 file_id=1270.

14. Marciano MA, Guimaraes BM, Ordinola-Zapata R, Bramante CM, Cavenago BC, Garcia RB, et al. Physical properties and interfacial adaptation of three epoxy resin-based sealers. J Endod. 2011;37(10):1417-21. doi:10.1016/j.joen.2011.06.023
15. Heyder M, Kranz S, Volpel A, Pfister W, Watts DC, Jandt $\mathrm{KD}$, et al. Antibacterial effect of different root canal sealers on three bacterial species. Dent Mater. 2013;29(5):542-9. doi:10.1016/j.dental.2013.02.007

16. Nawal RR, Parande M, Sehgal R, Naik A, Rao NR. A comparative evaluation of antimicrobial efficacy and flow properties for Epiphany, Guttaflow and AH-Plus sealer. Int Endod J. 2011;44(4):307-13. doi:10.1111/j.1365-2591.2010.01829.x

17. Tran QH, Nguyen VQ, Le AT. Silver nanoparticles: synthesis, properties, toxicology, applications and perspectives. Adv Nat Sci Nanosci Nanotechnol 2013;4:1-20. doi:10.1088/2043-6262/4/3/033001

18. Marambio-Jones C, Hoek EV. A review of the antibacterial effects of silver nanomaterials and potential implications for human health and the environment. J Nanopart Res. 2010;12(5):1531-51. doi:10.1007/s11051-010-9900-y

19. Wu D, Fan W, Kishen A, Gutmann JL, Fan B. Evaluation of the antibacterial efficacy of silver nanoparticles against Enterococcus faecalis biofilm. J Endod. 2014;40(2):285-90. doi:10.1016/j.joen.2013.08.022

20. Kayaoglu G, Orstavik D. Virulence factors of Enterococcus faecalis: relationship to endodontic disease. Crit Rev Oral Biol Med. 2004 Sep 1;15(5):308-20.

21. Dornelles-Morgental R, Guerreiro-Tanomaru JM, Faria-Junior NB, Hungaro-Duarte MA, Kuga MC, Tanomaru-Filho M. Antibacterial efficacy of endodontic irrigating solutions and their combinations in root canals contaminated with Enterococcus faecalis. Oral Surg Oral Med Oral Pathol Oral Radiol Endod. 2011;112(3):396-400. doi:10.1016/j.tripleo.2011.02.004

22. Tobias RS. Antibacterial properties of dental restorative materials: a review. Int Endod J. 1988;21(2):155-60.

23. Anumula L, Kumar S, Kumar VS, Sekhar C, Krishna M, Pathapati RM, et al. An assessment of antibacterial activity of four endodontic sealers on Enterococcus faecalis by a direct contact test: an in vitro study. ISRN Dent. 2012;2012:989781. doi:10.5402/2012/989781

24. Hume WR. The pharmacologic and toxicological properties of zinc oxide-eugenol. J Am Dent Assoc. 1986 Nov;113(5):789-91.

25. Kayaoglu G, Erten H, Alacam T, Orstavik D. Short-term antibacterial activity of root canal sealers towards Enterococcus faecalis. Int Endod J. 2005;38(7):483-8. doi:10.1111/j.1365-2591.2005.00981.x

26. Liu P, Guan R, Ye X, Jiang J, Liu M, Huang G, et al. Toxicity of nano- and micro-sized silver particles in human hepatocyte cell line L02. J Phys Conf Ser. 2011;304(1). doi:10.1088/1742-6596/304/1/012036

27. Kvitek L, Panacek A, Soukupova J, Kolar M, Vecerova R, Prusek R, et al. Effect of surfactants and polymers on stability and antibacterial activity of silver nanoparticles (NPs). J Phys Chem C. 2008;(15):5825-34. doi:10.1021/jp711616v 